\title{
LAS PRINCIPALES DEFICIENCIAS EN EL FUNCIONAMIENTO DEL SISTEMA DEMOCRÁTICO EN ESPAÑA A LOS TREINTA Y CINCO AÑOS DE SU CONSTITUCIÓN
}

[The Main Deficiencies of How the Democratic System Works in Spain Thirty Five Years After its Constitution Was Drafted]

\author{
Fernando Martínez Arribas* \\ Universidad de Vigo, España
}

\begin{abstract}
RESUMEN
La vigente Constitución española fue adoptada en el año 1978. Pasados treinta y cinco años y en el marco de una fuerte desconfianza hacia el sistema político, resulta conveniente efectuar un análisis de las principales deficiencias del modelo establecido. En este sentido, se aborda el funcionamiento de la democracia representativa, a través del análisis de las principales características y efectos del sistema electoral; y la operatividad de
\end{abstract}

\begin{abstract}
The current Spanish Constitution was adopted in 1978. After thirty five years and within the context of a strong distrust of the political system, the main deficiencies of the established model should be analyzed. In this sense, the way in which the representative democracy works is addressed by way of the analysis of the main characteristics and effects of the electoral system and how the direct democracy mechanisms operate, mainly,
\end{abstract}

Recibido el 27 de marzo y aCePtado el 21 de junio de 2014

* Doctor en derecho público y teoría del Estado por la Universidad de Santiago de Compostela, España. Profesor de ciencia política y de la administración en la Universidad de Vigo y profesor-tutor de derecho constitucional de la Universidad Nacional de Educación a Distancia (UNED) en el Centro Asociado de Lugo (España). Correo electrónico: fernando.martinez@uvigo.es El autor agradece a Antonio-Carlos Pereira Menaut, profesor de derecho constitucional de la Universidad de Santiago de Compostela, la lectura del texto inicial. 
los mecanismos de democracia directa, mayormente el referéndum y la iniciativa legislativa popular.

\section{Palabras Clave}

Democracia representativa - Democracia directa. the referendum and the people's legislative initiative.

KEYWORDS

Representative democracy - Direct democracy.

\section{El actual contexto en España}

Han transcurrido más de treinta y cinco años de vigencia de la Constitución española ${ }^{1}$, tiempo suficiente para afianzar el modelo diseñado a partir de ella. No obstante, el actual contexto político, económico y social arroja algunas dudas sobre su grado de consolidación, lo que podría hacer necesario la introducción de diversos cambios que mejoren y actualicen este esquema institucional.

Es indudable que el régimen constitucional establecido en 1978 ha supuesto el período de democracia y bienestar (pese a la crisis económica que ahora vivimos) más importante de la moderna historia española, aunque la Constitución de 1876 todavía la supere formalmente en duración, no así en su éxito. En las últimas tres décadas, se ha desarrollado un Estado social y democrático de derecho (como recoge el artículo 1.1 de la Constitución española ( $=$ Cesp.), se ha articulado un Estado autonómico que, en muchos aspectos (no en todos) se parece a los sistemas federales, se ha reducido el atraso secular de España, y se ha producido la adhesión a la Organización del Tratado del Atlántico Norte (OTAN-NATO) y a la Unión Europea (UE).

No obstante, lejos de caer en la autocomplacencia, el año 2014 está demostrando los déficits del modelo que, en ciertos aspectos, se arrastraban desde la propia aprobación del texto constitucional. Así, el 9 de noviembre de este año está convocado un referéndum en Cataluña, una de las comunidades autónomas más relevantes tanto en el plano cuantitativo como cualitativo, impulsado por el presidente de la Generalitat catalana, en el que se formularán las cuestiones: ¿Quiere que Cataluña se convierta en un Estado? y ¿Quiere que este Estado sea independiente? A pesar de que tenemos muchas dudas acerca de la celebración efectiva de este referéndum, no

${ }^{1}$ Aprobada por las Cortes Generales (Congreso de los Diputados y Senado) en sesiones plenarias celebradas el 31 de octubre de 1978, ratificada por referéndum el 6 de diciembre de 1978, y en vigor desde el 29 de diciembre de ese año. 
consensuado con el Gobierno central, lo que parece traslucir es que el modelo abierto de la Constitución en cuanto a la organización territorial (título $8^{\circ}$ ), que probablemente había sido la solución más razonable en aquel momento para poder consensuarla (recordemos que fue respaldada por el $87,78 \%$ de los votantes con una participación del 58,97\%) está convirtiéndose ahora en un factor de inestabilidad.

Paralelamente, no se puede dejar de mencionar el contexto derivado de la brutal crisis económica que desde hace años afecta a España, con cifras alarmantes de desempleo (de más del 26\% en la Encuesta de Población Activa del último trimestre del 2013, lo que se traduce en cerca de seis millones de desempleados). De forma más singularizada, puede detectarse una situación de enorme desconfianza hacia los órganos constitucionales del Estado: el Tribunal Constitucional es objeto de permanente controversia dada la forma de elección de sus miembros, estando su propio presidente cuestionado por pertenecer en su momento al actual partido gobernante; el presidente del Tribunal Supremo se vio forzado a dimitir en el año 2012 a raíz de un confuso asunto relativo al pago de viajes privados; el actual partido gobernante está siendo investigado por prácticas presuntamente corruptas, al igual que antiguos dirigentes autonómicos pertenecientes al principal partido de la oposición; el anterior presidente de la patronal empresarial ha sido detenido y condenado en un procedimiento judicial; los sindicatos están bajo sospecha; e, incluso, la familia real ha visto reducido su apoyo popular a raíz de diversos incidentes y el comportamiento, calificado como "no ejemplar" por la propia Casa Real, del esposo de una de las Infantas.

Todo ello tiene su reflejo en que España pierde diez posiciones en el Índice de Percepción de la Corrupción ${ }^{2}$ correspondiente al año 2013: ocupa el puesto 40 cuando el año 2012 tenía el número 30 (en el mismo índice, Chile ocupa el puesto 22).

Si observamos los datos del Centro de Investigaciones Sociológicas $(\mathrm{CIS})^{3}$ podemos hacernos una idea de la dificultad del momento: la situación política de España es calificada como mala o muy mala por el $81,8 \%$ de los encuestados (suma del 31,4 que la consideran mala y del 50,4 muy mala); la corrupción y el fraude aparecen como el segundo problema de España (con un 39,5\%) sólo precedida por el paro, mientras que los políticos en general, los partidos y la política, ocupan el cuarto lugar (con un relevante 26,9\%).

${ }^{2}$ Índice elaborado por Transparency Internacional. Si 100 puntos significan ausencia de corrupción y 0 percepción de país muy corrupto, España tiene 59 puntos. Estaría por debajo de los países nórdicos pertenecientes a la Unión Europea que encabezan esta lista, de los países del Benelux (Holanda, Bélgica y Luxemburgo), de estados como Alemania, Reino Unido o Francia, y también de otros como Irlanda, Portugal o Polonia.

${ }^{3}$ Barómetro del CIS de enero de 2014 (estudio No 3011). 
La valoración del Gobierno es desastrosa (el 70,8 hacen de él una valoración mala o muy mala) pero la del principal partido de la oposición igualmente está bajo mínimos (el mismo porcentaje la consideran mala o muy mala). El resultado es que el bipartidismo imperfecto de las últimas tres décadas parece estar en cuestión, aunque ya anticipamos que el sistema electoral ofrece a los principales partidos un margen de seguridad: si en las últimas elecciones generales de 2011, la suma de sufragios del Partido Popular y del Partido Socialista suponía el $73,4 \%$ de los votos, la estimación realizada por el CIS reduce este porcentaje al 58,7 en enero de 2014. Si comparamos estos datos con las elecciones anteriores (en el año 2008 sus votos representaban conjuntamente el 83,8\%) vemos cómo la posición decreciente de los dos principales partidos políticos del país se está agravando. A ello habría que sumar el incremento de la abstención o de los votos en blanco, que el cis sitúa ya en el $8,1 \%$ y que podrían situarse entre ciudadanos descontentos con el funcionamiento del sistema.

Sin duda, en este cuadro general, no podemos olvidar que alguna de estas inquietudes se fueron planteando a partir del nacimiento del Movimiento 15-M, en el año 2011, que tuvo en su momento gran repercusión mediática y abogaba, entre otras cuestiones que exceden a este trabajo, por fortalecer los mecanismos de participación ciudadana. La suma de todo ello puede y debe llevarnos a que nos preguntemos por el funcionamiento del sistema democrático en España a día de hoy.

\section{II. ¿UN MODELO RERESENTATIVO REALMENTE REPRESENTATIVO?}

Aunque en los orígenes del Estado Constitucional, los conceptos de democracia y representación eran contradictorios e incluso excluyentes, la evolución experimentada por el constitucionalismo a lo largo de tres siglos acabó por dibujar la noción de democracia representativa ${ }^{4}$. En palabras del insigne profesor Loewenstein "fue la técnica de la representación la que hizo

${ }^{4}$ Torres del Moral, Antonio: Estado de Derecho y democracia de partidos (Madrid, Universitas, 2012), pp. 390-391, precisa que los regímenes emanados de las revoluciones burguesas de finales del siglo XVIII no pueden calificarse de democracia. La democracia, entendida como autogobierno directo del pueblo no sería lo pretendido por Montesquieu, De Lolme, Sieyès o los "founding fathers" de los Estados Unidos, que "buscaron proteger el régimen de la influencia del "populacho". De esta forma, se diferenciaron los conceptos de "pueblo" y "nación" de modo que la soberanía nacional no necesitaba del sufragio universal; paralelamente, comenzó a llamarse "democracia" al gobierno representativo sobre la base de que gobernaban los representantes de la nación, de ahí que Condorcet utilizara la noción de "democracia representativa" ya en 1787. 
posible la institución del parlamento como un detentador del poder separado e independiente del Gobierno"s.

De hecho, el fundamento de dicho modelo, con Montesquieu y Sieyès a la cabeza, "consiste en identificar la voluntad de los representados con la de los representantes", habiéndose generalizado el gobierno representativo en todos los países democráticos ante la imposibilidad, en la sociedad actual, "de regir la vida pública "sin la intermediación de la representación política" . Pero esa identificación de voluntades se estableció precisamente a partir del rechazo a las instrucciones que los representados pudieran dar a sus representantes, como aclaró el propio Edmund Burke en su Discurso a los electores de Bristol de 1774.

En el caso de España, el artículo 23 de la Constitución de 1978 consagra la democracia representativa, afirmando el propio Tribunal Constitucional (sentencia $\mathrm{N}^{\circ} 119 / 1995$, de 17 de julio) que la democracia se ejerce (de modo fundamental, aunque no exclusivamente) a través de las instituciones representativas ${ }^{8}$. No obstante, debemos tener presente que la democracia directa también encuentra su fundamento en el mismo artículo 23, que recoge ambas vertientes siguiendo la estela del artículo 21 de la Declaración universal de derechos humanos y del artículo $25 \mathrm{del}$ Pacto internacional de derechos civiles $y$ políticos. Bien es cierto que, como veremos más adelante, treinta y cinco años de régimen constitucional han demostrado que existe amplio margen de mejora en este ámbito (véanse los ejemplos de Suiza o los Estados Unidos) y así parece demandarlo, al menos, una parte de la sociedad española.

Llegados a este punto, detectamos importantes problemas en el funcionamiento de la democracia representativa española que exceden el ámbito de este trabajo. El sistema parlamentario bicameral no funciona adecuadamente, pues el Senado no cumple las funciones de representación territorial que la propia Constitución le encomienda, al tiempo que está disminuido en relación

${ }^{5}$ Loewenstein, Karl, Teoría de la Constitución (2a edición española, Barcelona, Ariel, 1976), p. 60. Por ello, afirma que "la invención o descubrimiento de la técnica de la representación ha sido tan decisiva para el desarrollo político de Occidente y del mundo, como ha sido para el desarrollo técnico de la humanidad la invención del vapor, la electricidad, el motor de explosión o la fuerza atómica”.

${ }^{6}$ Oliver Araujo, Joan, Los sistemas electorales autonómicos (Barcelona, Institut d'Estudis Autonòmics, 2011), p. 24.

${ }^{7}$ Ibíd., p. 25, citando a PÉRez Alberdi, María Reyes, Democracia y participación, en Revista Catalana de Dret Públic, 37 (2008), p. 358.

${ }^{8}$ A tal efecto, véase el Fundamento Jurídico № 3 de la antedicha sentencia: "Para que la participación regulada en una Ley pueda considerarse como una concreta manifestación del a rtículo 23 CE es necesario que se trate de una participación politica, es decir, de una manifestación de la soberanía popular, que normalmente se ejerce a través de representantes y que, excepcionalmente, puede ser directamente ejercida por el pueblo [...]". 
al Congreso de los Diputados en su papel como legislador. La posición del mismo Congreso como Cámara legislativa cada vez es menos importante, no sólo porque la gran mayoría de las leyes tienen origen en el Gobierno (los proyectos de ley) sino porque los diferentes ejecutivos hacen un uso amplio de la facultad constitucional de aprobar decretos-leyes (artículo 86) o decretos legislativos (artículos 82-85). Además, los diputados, liberados del mandato imperativo en relación con su electorado (artículo 67.2), están sometidos a un mandato imperativo de facto en relación al partido político al que pertenecen, siendo escasos los supuestos en los que esta "disciplina" se rompe, a lo que sin duda contribuyen unas listas electorales cerradas y bloqueadas?. Paralelamente, creemos que los mecanismos políticos de control de la acción gubernamental son manifiestamente mejorables (véanse las dificultades para constituir comisiones de investigación o de acceso a la documentación), sobre todo en los casos de existencia de mayorías absolutas. A lo anterior, habría que añadir una controvertida praxis en lo concerniente a la elección de determinados órganos constitucionales (véase el Tribunal Constitucional o el Consejo General del Poder Judicial, pero también otros organismos de naturaleza consultiva o asesora), en los que el papel de los diputados (y senadores) es fundamental en la teoría, pero que en la práctica funcionan en ocasiones como un "sistema de cuotas" entre los principales partidos políticos.

No obstante, sólo nos detendremos en uno de los aspectos que más polémica genera: la regulación del sistema electoral en España, centrándonos fundamentalmente en la normativa prevista para la elección del Congreso de los Diputados. Y ello por la estrecha relación entre representación política y sistema electoral, ya que "para un enfoque adecuado de la representación política, debemos considerar y analizar los diversos sistemas electorales, desde el momento de la democracia representativa se traduce en hallar la más idónea manera de elegir a los representantes, implementando un "sistema electoral" que satisfaga los objetivos buscados. Uno de los propósitos más relevantes es que el sistema logre una mayor y mejor "representatividad" del elegido en relación con el elector. De esta manera, indiscutiblemente el

${ }^{9}$ El profesor Pereira Menaut, Antonio Carlos, Na procura do mellor sistema electoral para Galicia, en Torres del Moral (director) - Martínez Arribas (coordinador), Análise das eleccións autonómicas galegas do 21 de outubro de 2012: Reflexións sobre o sistema electoral (Santiago de Compostela, Andavira, 2013), p. 85, afirma que "De este modo llegamos a la paradoja de que el mandato imperativo del demos sea ilegal en una democracia (aparte de poco viable, pero esa es otra historia), mientras que se practica con frecuencia el mandato imperativo del partido (prohibido de iure; habitual e incluso oficializado en la práctica)". 
sistema electoral se constituye en el elemento más importante de la democracia representativa" 10 .

\section{Breves consideraciones sobre los sistemas electorales ${ }^{11}$.}

No podemos detenernos en un análisis detallado relativo a los sistemas electorales, sus elementos, efectos y, por ende, disfunciones. Ahora bien, no por ello omitiremos alguna consideración sobre ellos.

El sistema electoral puede concebirse como el "conjunto de reglas y procedimientos conforme a los cuales se convocan y celebran las elecciones, se asignan los escaños a tenor de los votos obtenidos por las candidaturas y se resuelven los recursos a que todo este proceso diere lugar" 12 .

De este modo, a partir de las combinaciones que se produzcan entre los elementos básicos del sistema electoral, sintetizados por Nohlen en la distribución de las circunscripciones, la forma de la candidatura, los procesos de votación y los métodos de conversión de votos en escaños ${ }^{13}$, el sistema será más o menos representativo (y también puede producir resultados electorales diferentes).

Comenzando por el tamaño de las circunscripciones y la distribución de escaños dentro de las mismas, se define la talla de un parlamento como "la primera pieza de la representación, básicamente porque según sea alta o baja está afectada por el carácter probabilístico de su representatividad estadística, de manera que lo más frecuente es que, de no cumplirse unos mínimos numéricos elevados, condicione la proporcionalidad básica del sistema de representación" ${ }^{14}$. Y ligada directamente a la talla aparece el coeficiente electoral, que tendría "un carácter cualitativo y viene definido por el número

${ }^{10}$ Banda Vergara, Alfonso, Democracia representativa y sistema electoral, en Revista de Derecho, 12 (Valdivia, 2001) 2, p. 26.

${ }^{11}$ Para la redacción de este apartado se han utilizado planteamientos de este autor reflejados en MARTínez ARRIBAs, Fernando, Reflexiones sobre la non nata reforma de la Lei de Eleccións ao Parlamento de Galicia, en Dereito. Revista xurídica da Universidade de Santiago de Compostela, 21 (2012) 2, pp. 4-9.

${ }^{12}$ Torres del Moral, Antonio, Estado, cit. (n. 4), p. 411.

${ }^{13}$ Nohlen, Dieter, Sistemas electorales y partidos políticos (México, Fondo de Cultura Económica, 2004), p. 34. No podemos olvidarnos de otros elementos comunes a los sistemas electorales en los que ahora no entraremos: la administración electoral, el censo electoral, la campaña electoral y, sobre todo, el derecho de sufragio (tanto activo como pasivo), entendido en su dimensión universal, a través de una larga evolución que culminó en la eliminación de las restricciones que operaban en él (por renta, sexo, etc.), ejercitado de modo libre, igual y secreto (y en el caso español, para las elecciones al Congreso y Senado, también directo).

${ }^{14}$ Llera Ramo, Francisco, El predominio del bipartidismo imperfecto, en Reis, 82 (1998), p. 135. 
de electores potenciales que, por término medio, puede representar cada parlamentario"15; a partir de aquí ya tenemos, según los casos, la ratio entre escaños y población o entre escaños y electores. En este sentido, se puede establecer una regla general: "cuanto más pequeña es la circunscripción electoral, menor es el efecto proporcional del sistema electoral; esto significa que disminuyen las posibilidades electorales de los partidos pequeños" ${ }^{16}$. A su vez, las circunscripciones pueden ser uninominales, en las que se elige un único escaño (caso actual del Reino Unido), y plurinominales, escogiendo más de un escaño (la regla general en España y también en Chile, a través de un sistema de circunscripciones binominales).

La forma de la candidatura conformaría otro de los elementos centrales del sistema electoral. Así, pueden existir candidaturas unipersonales (como en las elecciones legislativas británicas o francesas) o de listas (como en el caso español). Las listas, a su vez, pueden ser abiertas, en las que el elector puede combinar candidatos de diferentes formaciones políticas (como ocurre en España con los senadores que se eligen por sufragio universal en circunscripciones provinciales); cerradas y no bloqueadas, en las que el elector puede escoger a sus representantes dentro de la lista propuesta por la formación política; y cerradas y bloqueadas (en las elecciones españolas al Congreso de los Diputados), donde el elector no puede efectuar ninguna alteración a la propuesta de lista planteada por los partidos políticos, lo que otorga a éstos (y, en particular, a sus órganos directivos) un enorme poder.

En lo que respecta a los procesos de votación, frecuentemente vinculados a la forma de la candidatura, podemos mencionar una amplia diversidad de posibilidades que ahora nos limitamos a enunciar: voto único (el elector sólo dispone de un voto, lo que encaja plenamente con un sistema de listas cerradas y bloqueadas); preferencial (el votante puede expresar su preferencia por un candidato determinado, lo que ya se daría en listas cerradas no bloqueadas); múltiple (el elector tendría tantos votos como escaños de la circunscripción); múltiple limitado (el elector tendría varios votos pero menos que el total de escaños de la circunscripción); alternativo (el votante puede indicar sucesivamente varias preferencias); acumulado (el elector puede acumular varios votos a favor de un candidato); "panachage" (el votante puede distribuir sus votos entre candidatos de listas diferentes, como en el caso de las listas abiertas); doble voto (el elector tiene dos votos, uno por el candidato que presenta cada partido en cuanto circunscripción uninominal, y otro por la lista que cada formación política presenta a nivel

\footnotetext{
${ }^{15}$ Ibíd.

${ }^{16}$ Nohlen, Dieter, cit. (n. 13), p. 57.
} 
de circunscripción plurinominal); y voto simultáneo (un único voto del elector sirve para dos o más decisiones ${ }^{17}$.

Finalmente, en cuanto a los métodos de conversión de los votos en escaños, debemos distinguir si el sistema electoral se configura como mayoritario o proporcional, lo que también incidirá en el tipo de circunscripción.

El modelo mayoritario, habitual en España hasta la promulgación de la Constitución de 1978, aparece actualmente ligado a las circunscripciones uninominales ${ }^{18}$, si bien Chile sea precisamente el ejemplo prototípico de sistema mayoritario con circunscripciones binominales. En estos modelos, el candidato o formación política que obtenga mayor número de votos en la circunscripción es el que ganará, no teniendo ninguna relevancia a efectos de escaños los votos obtenidos por otros candidatos o formaciones. Es el caso del Reino Unido, en las elecciones al Parlamento de Westminster (sistema mayoritario a una vuelta) o en las elecciones legislativas francesas (en este caso, a dos vueltas). El resultado favorece claramente la gobernabilidad, con la frecuente formación de mayorías absolutas con porcentajes de voto no muy elevados, aunque perjudica a los pequeños y medianos partidos (como el Partido Liberal Demócrata británico) distorsionando la relación entre el porcentaje de votos de una formación y los escaños obtenidos en el Parlamento, ya sea por exceso o por defecto ${ }^{19}$.

En cuanto al sistema proporcional, cuyo principio inspirador sería repartir

${ }^{17}$ Ibíd., p. 68.

${ }^{18}$ El sistema electoral español emanado de la "Ley La Cierva" (aprobada bajo de Gobierno de Maura en 1907) que, con algunas modificaciones, se mantuvo en vigor incluso durante la Segunda República, establecía un modelo mayoritario con circunscripciones plurinominales (las uninominales desaparecerían con la República). Los efectos mayoritarios de este modelo se atenuaban, en parte, impidiendo que el elector pudiese escoger tantos candidatos como escaños elegibles, lo que garantizaba la presencia de las minorías aunque en un porcentaje limitado (sistema no tan alejado al que existe actualmente en España para la elección del Senado). El propio modelo que se utiliza como referencia de circunscripciones uninominales (el Reino Unido) tuvo durante mucho tiempo circunscripciones binominales o incluso con más escaños.

${ }^{19}$ Las elecciones parlamentarias de 1983 son probablemente uno de los ejemplos más notorios de las distorsiones del sistema mayoritario británico: el Partido Conservador obtuvo con el $42,4 \%$ de los votos, el $61,1 \%$ de los escaños de la Cámara de los Comunes; el Partido Laborista, con el 27,6\% de los votos logró el 32,1\% de los escaños; y la alianza Partido Liberal-Partido Socialdemócrata, con el 25,4\% de los votos obtuvo el 3,5\% de los escaños. Incluso, el sistema mayoritario no garantiza que el partido con más votos sea el que tenga mayor número de escaños, como ocurrió en las elecciones de 1951, en la que el Partido Conservador tuvo más escaños que el Partido Laborista con menos votos que éste, y también en las de febrero de 1974 (en este caso los laboristas lograron mayor número de escaños que los conservadores a pesar de tener menor porcentaje de voto). 
los escaños de manera proporcional al número de votos obtenidos por cada formación política, existen diversos métodos para realizar esta operación: los métodos del divisor, siendo el más conocido la fórmula d'Hondt, dividiéndose los votos obtenidos por los diversos partidos entre series de divisores de los que resultan una serie de cocientes, los cuales se irán asignando de mayor a menor hasta completar el total de escaños de la circunscripción; y los métodos del cociente, en los que se establece un cociente electoral a partir del que se distribuyen los escaños, existiendo a su vez diferentes variantes (Hare, Hagenbach-Bischoff, Droop) ${ }^{20}$.

Como decíamos, la combinación de los diferentes elementos incidirá en los resultados del sistema, haciendo incluso que se aproximen los efectos de modelos teóricamente alejados. En España, la combinación de circunscripciones plurinominales pequeñas (que son la gran mayoría) y la utilización de la fórmula d'Hondt (el método menos proporcional entre los proporcionales) produce que el sistema proporcional de iure tenga sesgos claramente mayoritarios de facto, beneficiando en el reparto de escaños a las dos principales formaciones políticas. En Chile, el resultado no sería tan alejado partiendo de parámetros distintos (un modelo mayoritario de circunscripciones binominales), pues al disponer que para que resulten electos los dos candidatos de una misma lista tienen que doblar en votos a la siguiente (y si esto no se produce, se atribuye un escaño a cada una de las listas más votadas y dentro de ellas, a los candidatos más votados), se fortalece también un sistema formado por dos grandes bloques políticos ${ }^{21}$.

\section{La elección del congreso de los diputados: Un sistema proporcional poco} proporcional.

El sistema electoral español cuenta con una regulación inicial en el propio texto constitucional, a diferencia de lo que acontece, por ejemplo,

${ }^{20}$ Nohlen, Dieter, cit. (n. 13), pp. 71-81.

${ }^{21}$ Modelo no exento de críticas, pues muchas veces permite el triunfo del tercer candidato más votado en perjuicio del segundo, como le sucedió al futuro presidente de la República, Ricardo Lagos, en el año 1989, no consiguiendo el acta de senador siendo el segundo más votado de su circunscripción y pese a obtener el 30,62\% de los votos frente al 17,19\% del tercero (y ello porque la lista en la que concurría Lagos no dobló a la siguiente más votada: un 61,89\% frente a un 32,50\%). Apunta el profesor BRONFMAN VARGAS, Alan, Igualdad del voto y configuración del territorio electoral de los diputados en Chile, en Revista de Derecho de la Pontificia Universidad Católica de Valparaíso, 40 (2013) 1, p. 355, que "en la elección de diputados de diciembre de 2009, de los ciento veinte escaños en disputa diez fueron obtenidos por candidatos que alcanzaron la tercera posición". Además, puede darse el caso de que no consiga escaño el candidato más votado, si su lista queda en tercera posición (lo que sucedería recientemente en las elecciones del año 2013 con la candidata del Partido Progresista en el Distrito 30). 
en el caso chileno. El hecho de que a la hora de elaborar la Constitución ya se hubieran celebrado unas elecciones generales para las que se elaboró una norma electoral (el Real Decreto-Ley N ${ }^{\circ}$ 20/1977, de 18 de marzo, sobre Normas electorales) y la nefasta experiencia derivada de sistemas electorales implantados en anteriores momentos de la historia española, motivó que el constituyente tomara algunas decisiones al respecto. La gestación del modelo, como expone magníficamente el profesor Torres del Moral, partía de que el entonces presidente Suárez era partidario de atender las tesis de Duverger con el fin de desterrar un sistema electoral de mayoría que había producido la división de las dos Españas; ahora bien, como los sistemas proporcionales producían multipartidismo e incluso la atomización de las Cámaras, había que "arreglarlo", lo que se hizo primero en la Ley para la reforma politica aprobada por las Cortes franquistas el 18 de noviembre de 1976 y después en el citado Real Decreto-ley $N^{\circ} 20 / 1977$, de 18 de marzo, que escogió el método d'Hondt como fórmula electoral, fijó la barrera electoral en el $3 \%$ de los votos válidos por circunscripción y estableció la distribución de escaños por distrito electoral, lo que se convirtió en una pieza esencial del sistema al sobrerrepresentar a las provincias menos pobladas y desarrolladas que previsiblemente apoyarían, como así sucedió en las dos primeras convocatorias electorales, al partido gobernante ${ }^{22}$. Es decir, aunque no puede hablarse en puridad de la existencia de "gerrymandering"23, el sistema electoral español fue concebido (y así lo sigue siendo) para favorecer a los grandes partidos a través del modelo de distribución de escaños por circunscripción ${ }^{24}$.

Llegados a este punto, los redactores de la Constitución de 1978 tenían "casi todo el trabajo hecho" en materia electoral. En lo que se refiere al Con-

22 Torres del Moral, Antonio, "Prólogo" a Torres del Moral, Antonio (director) - Martínez Arribas, Fernando (coordinador), Análise das eleccións autonómicas galegas do 21 de outubro de 2012: Reflexións sobre o sistema electoral (Santiago de Compostela, Andavira, 2013), pp. 12-15. Como explica este autor, el Decreto-ley de 1977 asignó dos escaños fijos por provincia, uno a Ceuta y otro a Melilla, por lo que existiendo 50 provincias y contando el Congreso con 350 diputados, quedaban 248 para repartir por criterios poblacionales; teniendo presente que a las 18 provincias más pobladas de la época correspondían 169 de esos 248 escaños, quedaban únicamente 79 para las 32 restantes (ibíd. p. 14). De esta forma, en las circunscripciones menos pobladas el sistema se volvía de facto mayoritario.

${ }^{23}$ Esta denominación procede del antiguo gobernador de Massachusetts, Elbridge Gerry, que en el siglo XIX modificó una circunscripción electoral de Boston para obtener un resultado favorable; dado que la circunscripción resultante tenía forma de salamandra, se utilizó para definir estos supuestos la expresión "gerrymandering".

${ }^{24}$ No estamos ante una situación exclusivamente española, sino que es una práctica muy extendida; a tal efecto puede verse, para el caso chileno, el trabajo de BRONFMAN VARGAS, Alan, Igualdad, cit. (n. 21), pp. 353-392. 
greso, la Constitución dispone que su composición estará entre un mínimo de 300 y un máximo de 400 diputados elegidos por sufragio universal, libre, igual, directo y secreto en los términos que establezca la ley (artículo 68.1); configura la provincia como circunscripción correspondiendo a la ley electoral distribuir el número total de diputados, asignando una representación mínima inicial a cada provincia y distribuyendo los demás escaños en proporción a su población (artículo 68.2); establece que en su elección se emplearán criterios de representación proporcional (artículo 68.3); y que su mandato sea de cuatro años, salvo disolución anticipada de la Cámara (artículo 68.4). En lo que respecta al Senado, configurado constitucionalmente como Cámara de representación territorial (artículo 69.1), la Carta Magna omite la referencia a su elección conforme a criterios de representación proporcional (de hecho, la Ley para la reforma politica había determinado que su elección se inspiraría en criterios de escrutinio mayoritario), estableciendo que cada provincia elige cuatro senadores por sufragio universal, libre, igual, directo y secreto en los términos establecidos por la ley orgánica (artículo 69.2); un régimen especial para las provincias insulares y Ceuta y Melilla (artículos 69.3 y 4$)^{25}$, la posibilidad de que las comunidades autónomas elijan senadores (artículo 69.5) ${ }^{26}$ y un mandato de cuatro años, excepción hecha de la disolución anticipada de esta Cámara (artículo 69.6).

Así las cosas, el Gobierno socialista aprobó la vigente Ley Orgánica 5/1985, de 19 de junio, sobre Régimen electoral general (= LOREG.) que mantuvo los elementos centrales de la normativa del año 1977: composición del Congreso fijada en 350 diputados y mínimo de dos por provincia, distribuyéndose el resto en función de la población (artículo 162 LOREG.); así como la barrera electoral del 3\% por circunscripción, la fórmula d'Hondt y la configuración cerrada y bloqueada de las listas de candidatos que se presenten (artículo 163 LOREG.).

Estos caracteres son los que también explican alguna de las controversias del sistema. Si elaboramos un cuadro para visualizar el diferencial existente

\footnotetext{
${ }^{25}$ Gran Canaria, Mallorca y Tenerife escogerán cada una tres senadores; Ibiza-Formentera, Menorca, Fuerteventura, Gomera, Hierro, Lanzarote y La Palma elegirá uno en cada caso; y dos Ceuta y otros dos Melilla.

${ }^{26}$ Pero el número de senadores de extracción autonómica sería reducido: uno por cada Comunidad Autónoma y otro más por cada millón de habitantes, correspondiendo su elección a la Asamblea Legislativa o a su órgano colegiado superior (el Gobierno autonómico), de acuerdo con lo que establezcan los Estatutos de Autonomía y asegurando (en este caso) la adecuada representación proporcional. La forma de elección del Senado, donde la aportación de las comunidades autónomas es pequeña a pesar de ser teóricamente la Cámara que las representa, es uno de sus aspectos más controvertidos, lo que unido a unas limitadas funciones casi siempre supeditadas al Congreso, explican la necesidad de reforma de esta Cámara.
} 
en las últimas elecciones generales celebradas hasta la fecha (20 de noviembre de 2011) entre el porcentaje de voto y el de escaños obtenidos por las diferentes candidaturas con representación en el Congreso de los Diputados, obtenemos lo siguiente:

\begin{tabular}{|c|c|c|c|c|}
\hline & \% de votos & $\mathrm{N}^{\circ}$ de escaños & \% de escaños & Diferencial \\
\hline Partido Popular & 44,63 & 186 & 53,14 & $+8,51$ \\
\hline $\begin{array}{c}\text { Partido Socialista } \\
\text { Obrero Español }\end{array}$ & 28,76 & 110 & 31,42 & $+2,66$ \\
\hline zzquierda Unida & 6,92 & 11 & 3,14 & $-3,78$ \\
\hline $\begin{array}{c}\text { Unión, Progreso y } \\
\text { Democracia }\end{array}$ & 4,7 & 5 & 1,42 & $-3,28$ \\
\hline $\begin{array}{c}\text { Convergència y } \\
\text { Unió }\end{array}$ & 4,17 & 16 & 4,57 & $+0,4$ \\
\hline Amaiur & 1,37 & 7 & 2 & $+0,63$ \\
\hline $\begin{array}{c}\text { Partido } \\
\text { Nacionalista } \\
\text { Vasco }\end{array}$ & 1,33 & 5 & 1,42 & $+0,09$ \\
\hline Esquerra & 1,06 & 3 & 0,85 & $-0,21$ \\
\hline $\begin{array}{c}\text { Bloque } \\
\text { Nacionalista } \\
\text { Galego }\end{array}$ & 0,76 & 2 & 0,57 & $-0,19$ \\
\hline Coalición Canaria & 0,59 & 2 & 0,57 & $-0,02$ \\
\hline Compromís & 0,51 & 1 & 0,28 & $-0,23$ \\
\hline Foro Asturias & 0,41 & 1 & 0,28 & $-0,13$ \\
\hline Geroa Bai & 0,17 & 1 & 0,28 & $+0,11$ \\
\hline
\end{tabular}

La situación descrita en el cuadro anterior para las elecciones generales de 20 de noviembre de 2011, lejos de ser una excepción, muestra un marco general en el que los dos principales partidos en porcentaje de voto (Unión de Centro Democrático y Partido Socialista en las dos primeras elecciones; Partido Socialista y Alianza/Partido Popular en las siguientes) han estado sobrerrepresentados en cuanto a su número de escaños en todos los comicios celebrados, mientras que los siguientes partidos de ámbito estatal están infrarrepresentados (véase en el presente Izquierda Unida y Unión, Progreso y Democracia), y los partidos de implantación autonómica (como Convergència i Unió o el Partido Nacionalista Vasco) han tenido una sobrerrepresentación mucho más leve que la lograda por las dos primeras fuerzas políticas españolas ${ }^{27}$.

${ }^{27}$ El diferencial entre votos y escaños durante el período $1977-2008$ puede verse en Montero Gibert, José Ramón - Riera Sagrera, Pedro, El sistema electoral espa- 
De esta forma, las elecciones al Congreso de los Diputados en España muestran como la magnitud de las circunscripciones limita la proporcionalidad de la fórmula d'Hondt, favoreciendo con matices un sesgo mayoritario que beneficia a los partidos más grandes (Partido Popular y Partido Socialista), castiga o dificulta la representación de los partidos pequeños con apoyos dispersos por todo el ámbito estatal, a la vez que facilita la representación parlamentaria de los partidos nacionalistas o regionalistas que concentran sus votos en determinadas circunscripciones ${ }^{28}$, siendo el resultado una especie de bipartidismo imperfecto en el plano nacional, con uno o varios sistemas o subsistemas de partidos regionales ${ }^{29}$. A lo anterior todavía habría que añadir un último factor que incidiría en el reparto de escaños: la barrera electoral o cláusula de exclusión, que implica la necesidad de que las formaciones políticas alcancen el $3 \%$ de los votos válidos de la circunscripción para poder optar al reparto de escaños, como sucede en las elecciones al Congreso de los Diputados en España (artículo 163 LOREG.) ${ }^{30}$. La conclusión del modelo la expone sintéticamente Nohlen: "En España, la limitación real de la representación proporcional a raíz de la distribución de circunscripciones electorales, es mucho más significativa que las consecuencias de la barrera legal, cuyos efectos se pueden presentar sólo en las circunscripciones grandes"31.

Panorama que, pese a las distorsiones efectivas que se producen, ha sido avalado por el Tribunal Constitucional en diversos posicionamientos, negando la existencia de una obligación encaminada a buscar la proporcionalidad

nol: cuestiones de desproporcionalidad y de reforma, en Anuario de la Facultad de Derecho de la Universidad Autónoma de Madrid, 13 (2009), p. 235.

${ }^{28}$ Montero Gibert, José Ramón, El debate sobre el sistema electoral: rendimientos, criterios y propuestas de reforma, en Revista de Estudios Politicos, 95 (1997), p. 12.

${ }^{29}$ Cotarelo, Ramón - Bobillo, Francisco J., El sistema de partidos, en VidalBeneyto (editor), España a debate, I: La politica (Madrid, Tecnos, 1991), p. 18.

${ }^{30}$ En relación con la barrera legal española, el profesor MonTERo GIBERT, José Ramón, cit. (n. 28), pp. 12-13 apunta que, dada la magnitud de las circunscripciones "los escaños se reparten generalmente entre los dos primeros partidos, por lo que quedan sin representación muchos partidos que superan con creces esa barrera”, por lo que lo verdaderamente trascendente sería la barrera efectiva que se establecería de facto, y que el citado profesor sitúa en el 10,2\% (la segunda más alta entre los países occidentales después de la de Irlanda), En el ámbito autonómico hay barreras superiores a la estatal: en Galicia, por ejemplo, se sitúa en el $5 \%$ de los votos válidos de la circunscripción. Probablemente el caso más controvertido sea el de Canarias, que prevé una barrera del 6\% de los votos válidos en el conjunto de la Comunidad Autónoma (no de la circunscripción) o, con carácter alternativo, del 30\% de los votos en una circunscripción (que serían cada una de las islas del archipiélago canario); el propio Tribunal Constitucional consideró que la barrera canaria se situaba en el límite de lo constitucionalmente admisible (STC 225/1998, de 25 de noviembre).

${ }^{31}$ Nohlen, Dieter, cit. (n. 13), p. 71. 
máxima en la atribución de escaños (sentencia del Tribunal Constitucional $\mathrm{N}^{\circ} 75 / 1985$, de 21 de junio); aceptando que el legislador introduzca correcciones o modulaciones al principio de proporcionalidad a la hora de configurar la concreta variante a seguir (sentencia del Tribunal Constitucional $\mathrm{N}^{\circ} 193 / 1989$, de 16 de noviembre); y limitando la vulneración del artículo 23.2 Cesp. por desviaciones de proporcionalidad a supuestos de entidad desprovistos de un criterio objetivo y razonable que pudiera permitir justificarlas (sentencia del Tribunal Constitucional $\mathrm{N}^{\circ}$ 4/1992, de 13 de enero). Al margen del juicio crítico que pudiera hacerse sobre estos posicionamientos del Tribunal Constitucional, no puede olvidarse que este órgano interpreta la Constitución y ésta es la que fija, como vimos en su momento, que la provincia sea la circunscripción, que cada provincia tenga al menos un diputado o que la elección se haga atendiendo a criterios de representación proporcional, en vez de reflejar que la elección sea "por un sistema proporcional".

Esta situación ha desembocado en una insatisfacción hacia el sistema electoral, al menos por parte de los partidos políticos más perjudicados por el mismo. De hecho, el Consejo de Estado elaboró en el año 2009 un prolijo informe sobre la materia ${ }^{32}$, aunque, dado que el Gobierno decidió excluir de la petición de informe aquellos aspectos que necesitaran de reforma constitucional ${ }^{33}$, no entró en el análisis de diversas opciones, como la sustitución de la provincia como circunscripción por las comunidades autónomas, la creación de una circunscripción nacional para la elección de una parte de los diputados, la supresión de la representación mínima inicial, o la distribución de restos a nivel nacional ${ }^{34}$.

Centrándose en los aspectos relativos a la mejora de la igualdad de voto, con el fin de corregir (o atenuar) las "enojosas diferencias en el valor del sufragio, en función de la circunscripción en que se deposite el voto o de la candidatura en cuyo favor se emita" ${ }^{35}$, el Consejo de Estado propone diver-

${ }^{32}$ Informe del Consejo de Estado sobre las propuestas de modificación del Régimen Electoral General, 24 de febrero de 2009.

${ }^{33}$ La solicitud planteada por el Gobierno al Consejo de Estado, el 27 de junio de 2008, p. 4 decía: "En consecuencia, el Gobierno considera adecuado y conveniente el examen y la valoración de aquellas propuestas de reforma de la legislación electoral que, siendo compatibles con la Constitución, contribuyan a incrementar la calidad democrática del sistema politico y a facilitar el ejercicio del derecho de sufragio por los ciudadanos".

${ }^{34}$ GarRote DE Marcos, María, La improbable reforma del sistema electoral del Congreso de los Diputados. Comentario del Informe del Consejo de Estado sobre reforma del sistema electoral, en In Dret, 4 (2009), pp. 12.

${ }^{35}$ Informe del Consejo de Estado, cit. (n. 32), p. 154. De esta forma, conseguir un escaño al Congreso de los Diputados en las circunscripciones de Madrid o Barcelona significa muchos más votos que, por ejemplo, en Soria o Segovia. Sobre esto puede verse FERNÁNDEZ SEGAdo, Francisco, La correlación entre el tamaño de las circunscripciones 
sas alternativas: aumentar a 400 el número de escaños (hoy en día, parece altamente improbable una decisión de esas características, habida cuenta de la percepción ciudadana sobre la clase política); disminuir la representación inicial mínima de cada provincia a un escaño (el efecto "rebote" de esta medida sería incrementar los efectos mayoritarios del sistema en las circunscripciones menos pobladas); sustituir la fórmula de reparto de escaños por otra más "proporcional"36; o que la base para el reparto de escaños no sea la población sino el censo. De ellas, el Consejo apuesta por una combinación entre el incremento del número total de diputados (50 más) y la reducción del mínimo provincial a uno, alternativas que "se han venido exigiendo en vía parlamentaria desde la tramitación de la Ley orgánica sobre régimen electoral general y han estado presentes en las propuestas de reforma planteadas por la mayoría de la doctrina ${ }^{37}$

No obstante, las perspectivas de una reforma de calado del sistema electoral a corto plazo son escasas: el Partido Popular no la tiene en la agenda, sino para reducir el número de diputados, como está impulsando en diversas comunidades autónomas ${ }^{38}$; y el Partido Socialista aboga por un desbloqueo limitado de las candidaturas, pero sin entrar en el reparto de escaños por circunscripciones. $\mathrm{Y}$ es que precisamente, ambas formaciones son las que obtienen una "prima" de escaños cuando ganan en votos, sin salir perjudicadas cuando quedan en segundo lugar, en un esquema que se reproduce desde

y las distorsiones de la proporcionalidad en la elección del Congreso, en Revista de Estudios Políticos, 79 (1993), pp. 305-400. Este autor establece un índice de representación proporcional por cada circunscripción (si el resultado es 1 la población de la provincia estaría justamente representada, si es inferior a 1 estaría infrarrepresentada, y si es superior a 1 estaría sobrerrepresentada) de modo que, en el momento de la elaboración de este trabajo, Soria tendría una sobrerrepresentación en relación con Madrid de 4,46 veces y Segovia con Barcelona de 2,85 veces (ibíd., p. 309). Estudio que, a pesar del tiempo transcurrido desde su publicación, muestra una tendencia que se sigue manteniendo.

${ }^{36}$ Informe del Consejo de Estado, cit. (n. 32), pp. 175-177. El Consejo de Estado consideraba que "la fórmula de efectos más proporcionales sería la Hare, seguida de la Droop y la Sainte-Laguë, y, en última instancia, estaría la D’Hondt” (ibíd., p. 191).

${ }^{37}$ Garrote de Marcos, María, cit. (n. 34), p. 25. Como dice esta autora, "La necesidad de aumentar el número de representantes se hace evidente si lo que se persigue es acercarse a una mayor proporcionalidad entre habitantes y diputados. Y, además, es una necesidad inaplazable, teniendo en cuenta que en el entorno europeo España tiene el promedio más alto de habitantes por diputado (un 153\% superior a la media), sólo por detrás de Alemania. Un incremento del número de representantes no sólo beneficiaría la lógica interna del sistema -protegiendo el principio de igualdad del voto y de proporcionalidad entre votos y escaños-, sino que también nos acercaría en este punto a la media europea de la que nos encontramos muy lejos en la actualidad".

${ }^{38}$ Sobre este particular, en concreto en el ámbito de la Comunidad Autónoma de Galicia, puede verse Martínez Arribas, Fernando, cit. (n. 11), pp. 1-33. 
el año 1982. Paralelamente, la introducción de mecanismos como el voto preferencial, privaría a las direcciones de los partidos de uno de sus principales instrumentos de control sobre los candidatos que presentan, como es la capacidad de decidir su posición en la lista electoral y, por consiguiente, predeterminar con cierto grado de seguridad si va a resultar electo.

\section{LOS LIMITADOS MECANISMOS DE DEMOCRACIA DIRECTA}

Aunque en el plano teórico la idea de democracia directa, conectada con lo practicado en las pólis de la Grecia clásica (bien es cierto que ejercitada sólo por los ciudadanos, lo que excluía a una parte considerable de su población) aparece como un objetivo a alcanzar, la realidad actual, sustentada en sociedades grandes (en extensión o población) y complejas, hace muy difícil su ejercicio.

En Europa, además, las fórmulas de democracia directa fueron vistas con cierta desconfianza, a lo que contribuiría el "cesarismo plebiscitario de Napoleón" ${ }^{39}$ posterior a la Revolución Francesa. Y ello porque, a pesar de que en el período comprendido entre las dos guerras mundiales hubo planteamientos para introducir estos mecanismos ante el desprestigio del parlamentarismo de la época ${ }^{40}$, la experiencia de la utilización de fórmulas plebiscitarias por "los regímenes anti democráticos del eje, restaría crédito a estos instrumentos" ${ }^{\prime 1}$, lo que ayudaría a explicar el poco aprecio del que gozan, por ejemplo, en la República Federal de Alemania.

No obstante, finalizada la Segunda Guerra Mundial sí se utilizó el referéndum para determinar aspectos fundamentales del Estado, como sucedió en Italia para suprimir la monarquía. Más adelante, De Gaulle utilizó esta figura para concebir un nuevo régimen constitucional (la $V$ República) y en el propio proceso de construcción de la Unión Europea han existido diversos

${ }^{39}$ Loewenstein, Karl, cit. (n. 5), pp. 82-84. Este autor recuerda que "Napoleón dio una legitimación democrática a su dominio al someter sus tres constituciones a plebiscito popular (1800, 1802, 1804)" (ibíd., p. 84).

${ }^{40}$ Véase, por ejemplo, Sснмітт, Carl, Sobre el parlamentarismo (Madrid, Tecnos, 1990).

${ }^{41}$ Alzaga Villaamil, Óscar - Gutiérrez Gutiérrez, Ignacio - Rodríguez Zapata, Jorge, Derecho politico español según la Constitución de 1978 (4a edición, Madrid, Editorial universitaria Ramón Areces, 2008), II, p. 152. En esta misma página se recoge cómo el líder laborista británico y antiguo Primer Ministro, Clement Attlee, se opuso a la posibilidad de celebrar un referéndum sugerida por Churchill, "puesto que no podría aceptar la incorporación en nuestra vida política de una institución ajena a nuestras tradiciones y que frecuentemente ha servido de instrumento al nazismo y al fascismo". 
referendos ${ }^{42}$, alguno de los cuales ha motivado renegociaciones y dilaciones en la vigencia de tratados previamente firmados, o que la propia "Constitución Europea" ${ }^{\not 3}$ no llegara a entrar en vigor ante el rechazo obtenido en las consultas populares de Francia y Holanda.

Por lo mismo, la iniciativa legislativa popular tampoco ha tenido una elevada aceptación en Europa, siendo una figura desconocida en la Ley Fundamental de Bonn y en la mayoría de los estados de la Unión Europea.

Ahora bien, a pesar de las reticencias hacia las fórmulas de democracia directa en el viejo continente y, con matices, en América Latina ${ }^{44}$, el texto constitucional español de 1978 decidió introducir algunas fórmulas de democracia directa que complementaran la democracia representativa. El artículo 23.1 Cesp. sería el reflejo de ello, aunque introduciendo diversos factores correctores que otorgaban una clara preeminencia al modelo representativo, como la eliminación de la posibilidad de convocar un referéndum por iniciativa popular para derogar o ratificar una ley aprobada por las Cortes Generales $^{45}$, a lo que habría que añadir las dificultades para ejercitar la figura de la iniciativa legislativa popular.

\section{El referéndum.}

La Constitución española de 1978 distingue tres modalidades de referéndum: el consultivo (artículo 92), el de reforma constitucional (artículos 167.3 y 168.3), y el de aprobación o reforma de Estatutos de Autonomía (artículos 151.1 y 3, y 152.2) sobre el que no nos detendremos en este trabajo. Tipologías cuyas condiciones y procedimiento se desarrollan en

\section{${ }^{42}$ Ibíd.}

${ }^{43}$ Tratado por el que se establece una Constitución para Europa, rubricado el 29 de octubre de 2004 por los Jefes de Estado y de Gobierno de la totalidad de los estados pertenecientes en ese momento a la Unión Europea.

${ }^{44}$ La vía del referéndum, en su dimensión plebiscitaria, se ha utilizado con relativa frecuencia en América Latina, siendo Chile, en la década de los ochenta del pasado siglo, uno de sus principales exponentes; más recientemente, puede destacarse, por su amplia repercusión, el caso de Venezuela. Hoy en día, se suceden los posicionamientos para introducir o fortalecer en América Latina estas fórmulas, como puede verse en Soto Barrientos, Francisco, El desafio de la participación. Referendo e iniciativa legislativa popular en América Latina y Europa (Santiago de Chile, Lom Ediciones, 2013). Sobre los instrumentos de democracia directa en Chile puede verse BronfMAN VARgas, Alan, Mecanismos de democracia directa en Chile: los plebiscitos y las consultas comunales, en Revista de Derecho de la Pontificia Universidad Católica de Valparaíso, 28 (2007) 1, pp. 237-265.

${ }^{45}$ Alzaga Villaamil, Óscar - Gutiérrez Gutiérrez, Ignacio - Rodríguez Zapata, Jorge, Derecho, cit. (n. 41), II, p. 153. Lo que lleva a estos autores a considerar que la Constitución de 1978 "es, de entre todas las occidentales aprobadas en los últimos cincuenta años, la más cauta frente a la figura del referéndum [...]”. 
la Ley Orgánica 2/1980, de 18 de enero, sobre Regulación de las distintas modalidades de referéndum.

Ahora bien, la regulación constitucional de esta figura se hizo de forma muy "mutilada", posiblemente ante la desconfianza que generaba en ciertos sectores políticos y sociales, al haber sido utilizada en el franquismo para tratar de perpetuar el régimen.

En lo que se refiere al referéndum consultivo ${ }^{46}$, será convocado por el rey, mediante propuesta del presidente del Gobierno previamente autorizada por el Congreso de los Diputados (artículo 92.2) ${ }^{47}$ para decisiones políticas de especial trascendencia (artículo 92.1). En cualquier caso, ni la Constitución ni la Ley Orgánica establecen los criterios para determinar cuando estamos ante una decisión de este tipo, lo que ha llevado a una escasísima utilización de esta figura, limitada a dos referendos en treinta y cinco años: el realizado en 1986 sobre la permanencia de España en la OTAN ${ }^{48}$ y el de la fallida "Constitución Europea" en el año 2005" ${ }^{49}$, triunfando en ambos casos la opción defendida por el Gobierno. Además, la figura prevista en el artículo 92 fue desnaturalizada en relación con lo previsto en el Anteproyecto constitucional, cuyo artículo 85 establecía la posibilidad de someter a referéndum "la aprobación de las leyes votadas por las Cortes Generales y aún no sancionadas, las decisiones politicas de especial trascendencia y la derogación de leyes en vigor'\$50. Así, además de un ámbito material notablemente superior, el Anteproyecto preveía que la iniciativa de la consulta popular podía partir no sólo del Gobierno, sino también de cualquiera de las Cámaras y

${ }^{46} \mathrm{El}$ artículo 92.1 Cesp. recoge expresamente su carácter “consultivo”. No obstante, la profesora Gómez Sánchez, Yolanda, Constitucionalismo multinivel. Derechos Fundamentales (Madrid, Sanz y Torres, 2011), p. 528, apunta que "el propio texto constitucional califica a este referéndum como consultivo estimando un sector doctrinal que tal término significaba que el resultado de la consulta popular no era vinculante para el Gobierno, tesis que es incompatible con la atribución de la soberanía al pueblo en el artículo 1.2 CE".

${ }^{47}$ El artículo 6 de la Ley Orgánica 2/1980 prevé que la autorización del Congreso de los Diputados sea por mayoría absoluta.

${ }^{48}$ Tuvo lugar el 12 de marzo de 1986 . El 52,5\% de los votantes se manifestó a favor, mientras que un 39,8\% votó en contra, siendo la participación del 59,4\%. Años después, España pasó a formar parte de la estructura militar integrada de la OTAN, siendo incumplida una de las condiciones establecidas en el propio referéndum para la permanencia de España en la OTAN, sin que fuera sometida a consulta popular.

${ }^{49}$ Referéndum celebrado el 20 de febrero de 2005 con la siguiente pregunta: “¿Aprueba usted el Tratado por el que se establece una Constitución para Europa?". El $76,73 \%$ de los votantes optó por el sí, el 17,24\% por el no y sólo un 6,03\% votó en blanco; la participación fue en este caso muy inferior al 50\% (el 42,32\%).

${ }^{50}$ Anteproyecto de Constitución, publicado en el Boletín Oficial de las Cortes, $\mathrm{N}^{\circ} 44$, de 5 de enero de 1978. 
de las Asambleas de tres Territorios Autónomos (equivalentes a los actuales Parlamentos autonómicos) e, incluso, cuando se tratara sobre la derogación de leyes en vigor, se permitía que la iniciativa pudiera partir de setecientos cincuenta mil electores. De nuevo, el deseo por establecer una democracia representativa sustentada en un sistema de partidos fuertes, parece que motivó que el texto finalmente adoptado poco tuviera que ver con lo propuesto inicialmente, lo que se hace patente hasta en la eliminación del apartado del Anteproyecto que decía que "el resultado del referéndum se impone a todos los ciudadanos y a todos los órganos del Estado".

En lo que respecta al referéndum de reforma constitucional, debemos aclarar que aunque se establece para los dos procedimientos de reforma, el ordinario del artículo 167 y el agravado del artículo $168^{51}$, sólo en este segundo caso la celebración de la consulta tendría carácter necesario y vinculante, puesto que en el caso del referéndum previsto en el artículo 167, únicamente se celebraría si así lo solicitaran una décima parte de los miembros de cualquiera de las Cámaras en los quince días siguientes a la aprobación parlamentaria de la reforma. Teniendo presente que, desde 1978, la Constitución española únicamente se ha reformado en dos ocasiones, modificando el artículo 13.2, por reforma de 27 de agosto de 1992, y el artículo 135, por reforma de 27 de septiembre de 2011, y en ninguna de ellas se ha celebrado referéndum, puede apreciarse con claridad la inoperatividad real de esta figura, de la que las "cúpulas" de los dos grandes partidos políticos estatales parecen querer huir.

De lo expuesto se desprende la necesidad de un cambio en la regulación del referéndum: dos cuestiones sometidas al escrutinio de la ciudadanía pasados más de treinta y cinco años del referéndum de ratificación de la propia Constitución resultan un bagaje demasiado escaso; más sorprendente todavía si tenemos en cuenta que en este período España ha ratificado diversos Tratados derivados de su pertenencia a la Unión Europea, que suponen cesión del "ejercicio" de competencias, sin que se haya celebrado consulta popular (excepción hecha de la fallida "Constitución Europea"). $\mathrm{Al}$ mismo tiempo, parece llegado el momento de replantearse la figura del referéndum legislativo, pues no creemos que su implantación (dependiendo en qué condiciones) pudiera poner en peligro al sistema representativo hoy

${ }^{51}$ La vía del artículo 168 se utilizaría cuando se trate de una revisión total de la Constitución; o de modificaciones que afecten al Título Preliminar (título pórtico que acoge la concepción como Estado Social y Democrático de Derecho, la monarquía parlamentaria, o el principio de unidad y el derecho a la autonomía de nacionalidades y regiones), al capítulo $2^{\circ}$, sección $1^{\text {a }}$ del título $1^{\circ}$ (derechos fundamentales y libertades públicas), y al título $2^{\circ}$ (la Corona). Para la reforma del resto de materias, el procedimiento sería el previsto en el artículo 167. 
en día. No obstante, la actual situación política derivada de la convocatoria (unilateral) de un referéndum en Cataluña, enturbia las posibilidades reales de actualizar la regulación de este instrumento.

\section{La iniciativa legislativa popular ${ }^{2}$.}

De conformidad con el artículo 9.2 Cesp., por el que corresponde a los poderes públicos facilitar la participación de todos los ciudadanos en la vida política, y el artículo 23 , que consagra el derecho de participación en los asuntos públicos directamente o por medio de representantes, el artículo 87.3 Cesp. Dispone: "Una ley orgánica regulará las formas de ejercicio y requisitos de la iniciativa popular para la presentación de proposiciones de ley. En todo caso se exigirán no menos de 500.000 firmas acreditadas. No procederá dicha iniciativa en materias propias de ley orgánica, tributarias o de carácter internacional, ni en lo relativo a la prerrogativa de gracia".

Por consiguiente, el constituyente español estableció un instrumento por el que la ciudadanía directamente tuviera la facultad de proponer la adopción de determinadas leyes, inspirándose en el artículo 71 de la Constitución italiana de 1947. Situación diferente, por ejemplo, a lo que sucede en Chile, donde la iniciativa legislativa es atribuida por el artículo 65 Cesp. únicamente a la Cámara de Diputados, al Senado, o al presidente de la República.

No obstante, la complementariedad en España entre la iniciativa legislativa de origen representativo, ya sea procedente del Gobierno, del Congreso, del Senado (artículo 87.1), o de las Asambleas de las comunidades autónomas (artículo 87.2), y la iniciativa legislativa directamente impulsada por la ciudadanía, está lejos de producirse, existiendo una clara posición de inferioridad de la segunda respecto de la primera.

La explicación, aparte de que la complejidad y dimensión de las modernas sociedades actuales no facilita la toma de decisiones a través de mecanismos de democracia directa (bien es cierto que con las nuevas tecnologías se abren más posibilidades), puede encontrarse en las reservas o cláusulas de seguridad introducidas por la Constitución de 1978 a la hora de establecer este instrumento.

\footnotetext{
${ }^{52}$ Nos referiremos aquí preferentemente a la iniciativa legislativa popular "de ámbito estatal" regulada en el artículo 87.3 Cesp. En las 17 comunidades autónomas en que se divide España existen instrumentos similares, previstos en sus respectivos Estatutos de Autonomía y desarrollados por sus leyes autonómicas. Asimismo, la Ley 7/1985, de 2 de abril, reguladora de las Bases del régimen local, establece en su artículo 70 bis 2, modificado en el año 2003, la posibilidad de que los residentes en el municipio presenten propuestas en materias de competencia municipal si alcanzan un determinado número de firmas, previéndose incluso una posible consulta popular de ámbito local, conforme a los requisitos establecidos en el artículo 71 .
} 
Así, el artículo 87.3 exige un elevado número de firmas (500.000). Es decir, si actualmente existen 34.396.001 españoles censados ${ }^{53}$, el porcentaje de firmas requerido representaría al 1,45\% del censo. Porcentaje superior al establecido por los "institutos análogos" en la mayor parte de las comunidades autónomas españolas ${ }^{54}$, y muy superior al $0,20 \%$ previsto para la Iniciativa Ciudadana Europea, ya que el Tratado de la Unión Europea establece un millón de firmas, pero sobre una población de más de 500 millones $^{55}$. Al mismo tiempo, estos porcentajes son mucho más elevados que los fijados en la mayor parte de los estados de la Unión Europea en los que opera la iniciativa legislativa ciudadana ${ }^{56}$.

En lo relativo al ámbito material, el artículo 87.3 prohibía el ejercicio de esta iniciativa en materias que hubieran de ser reguladas por ley orgánica, tuvieran carácter tributario o internacional, o versaran sobre la prerrogativa de gracia. Centrándonos en las materias que deban ser objeto de ley orgánica, el artículo 81 Cesp. dispone que esta tipología normativa se utilizará para "las relativas al desarrollo de los derechos fundamentales y de las libertades públicas, las que aprueben los Estatutos de Autonomía y el régimen electoral general y las demás previstas en la Constitución”. Es decir, los ámbitos sustantivamente más relevantes quedarían fuera de la iniciativa legislativa popular, corrigiendo lo que inicialmente reflejaba el Anteproyecto de texto constitucional, que no

53 "Censo Electoral de españoles residentes en España”, al 1 de febrero de 2014.

${ }^{54}$ En la Comunidad Autónoma de Galicia, en la que reside el autor de este trabajo, el número de firmas necesario es de 15.000 sobre un censo de 2.299 .184 (dato referido al censo electoral aplicable a los españoles residentes en Galicia para las elecciones autonómicas de 21 de octubre de 2012), lo que supone un porcentaje del 0,65\%.

${ }^{55} \mathrm{La}$ iniciativa ciudadana europea, prevista en el artículo 11.4 del Tratado de la Unión Europea y en el artículo 24 del Tratado de funcionamiento de la Unión Europea, ha sido regulada por el Reglamento (UE) № 211/2011 del Parlamento Europeo y del Consejo, de 16 de febrero de 2011. El millón de firmas necesario debe proceder al menos de la cuarta parte de los estados (actualmente 7 de un total de 28) fijándose un mínimo por Estado (en el caso de España sería, a día de hoy, de 40.500, inferior en más de diez veces a lo que se pide en la iniciativa legislativa popular del artículo 87.3 Cesp.); además, se prevé la posibilidad de que sea presentada ante la Comisión y en el Parlamento Europeo a través de una audiencia pública. No obstante, también en el ámbito comunitario hay limitaciones a esta figura: no puede servir para revisar los tratados o ser manifiestamente contraria a los valores de la Unión, y es definida por la propia Unión Europea como una invitación para que la Comisión proponga un texto, sin que esté obligada a ello, exigiéndose únicamente que motive su negativa. Datos actualizados de las iniciativas ciudadanas europeas presentadas o en tramitación pueden verse en la web de la UE [visibles en http://ec.europa.eu/citizens-initiative/public/welcome?lg=es].

${ }^{56}$ Italia sería el ejemplo prototípico de porcentajes bajos: 50.000 firmas con un censo electoral de más de 52 millones, lo que representa aproximadamente un 0,10\%. 
excluía a las leyes orgánicas del ámbito material de esta figura ${ }^{57}$. Lo mismo puede decirse de la reforma de la Constitución, vedada a la iniciativa legislativa popular en la versión final del artículo 166, pero no así en el artículo 157 del Anteproyecto, que admitía la iniciativa de reforma constitucional "en los términos del artículo $80^{158}$. Por tanto, la Constitución definitivamente adoptada vetó la utilización de esta iniciativa para las cuestiones de mayor calado e, incluso, impidió que pudiera plantearse la reforma de la Constitución a partir de una iniciativa legislativa popular, cambiando la versión primigenia emanada de la Ponencia constitucional.

Es más, la Ley Orgánica 3/1984, de 26 de marzo, reguladora de la iniciativa legislativa popular, adoptada en cumplimiento del mandato constitucional, aumenta en su artículo 2.5 el ámbito de exclusión material, ya que esta iniciativa tampoco podría versar sobre los ámbitos previstos en los artículos 131 (planificación de la actividad económica general) y 134.1 Cesp. (elaboración y aprobación de los Presupuestos generales del Estado). Y es que cuando se aprueba la ley reguladora de esta figura, en el año 1984, seguía existiendo una gran desconfianza hacia la iniciativa legislativa popular, como quedaba de manifiesto en el lenguaje utilizado por el "Preámbulo" originario de la ley, modificado parcialmente en el año 2006: "La regulación constitucional de la iniciativa legislativa popular recoge asimismo, las limitaciones propias de este instituto, derivadas de las enseñanzas históricas, que demuestran la facilidad con que el recurso al pronunciamiento popular directo puede servir de fácil cauce para manipulaciones demagógicas o, incluso, para intentar legitimar con un supuesto consenso popular, lo que no es en sustancia sino la antidemocrática imposición de la voluntad de una minoria", texto éste al que le fue suprimida la parte que comenzaba con "que demuestran".

Por si el número de firmas y las materias vetadas no fueran suficientes, el legislador estableció en la Ley Orgánica 3/1984 una tramitación no exenta de complicaciones y que otorga escaso papel a los promotores de la iniciativa.

Así, existirá un trámite de admisión previo ante la Mesa del Congreso, que se pronunciará en el plazo de 15 días sobre los requisitos establecidos en el artículo 5 de la ley para inadmitir la proposición: que verse sobre materias excluidas; que carezca de texto articulado y exposición de motivos, así como la relación de miembros de la Comisión Promotora; que verse sobre

${ }^{57}$ En este sentido, puede verse el artículo $80.4 \mathrm{del}$ Anteproyecto de Constitución, publicado en el Boletín Oficial de las Cortes, № 44, de 5 de enero de 1978.

${ }^{58}$ Como acabamos de ver, insertado en ese artículo 80 estaba la iniciativa legislativa popular. Por el contrario, la redacción definitiva del artículo 166 Cesp. estableció que "La iniciativa de reforma constitucional se ejercerá en los términos previstos en los apartados 1 y 2 del artículo 87”, excluyéndose el apartado tercero relativo a la iniciativa legislativa popular. 
materias manifiestamente distintas y carentes de homogeneidad entre sí; la existencia en el Congreso o el Senado de un proyecto o proposición de ley que verse sobre el mismo objeto de la iniciativa popular y que esté, cuando ésta se presenta, en el trámite de enmiendas u otro más avanzado; y que sea reproducción de otra iniciativa popular de contenido igual o sustancialmente equivalente presentada durante la legislatura en curso. Si bien la ley permite la posibilidad de recurrir la resolución de la Mesa del Congreso en amparo ante el Tribunal Constitucional, la realidad demuestra que, según las estimaciones efectuadas por el investigador Martínez Jiménez, el 39\% de las propuestas de iniciativa legislativa popular no superan este trámite ${ }^{59}$.

En cuanto a la recogida de firmas, que sólo se produciría una vez conseguida la admisión y para la que se otorga un plazo de nueve meses (que puede ser prorrogado en tres meses por la Mesa cuando concurra una causa mayor), este mismo autor apunta que, de las que lograron llegar a esta fase, el 75\% no consiguieron el número de rúbricas requerido.

Finalmente, los pocos casos que logren superar el trámite previo de admisión (artículo 5) y de firmas (artículos 7-12) aún tendrán que someterse a un nuevo filtro: la toma en consideración parlamentaria; es decir, un debate en el que los parlamentarios decidirán si van a entrar en el fondo de esa iniciativa para que siga su tramitación como proposición de ley (artículo 13). Así, hasta el final de la X legislatura (año 2011), conforme a los datos proporcionados por el antedicho investigador, únicamente obtuvo el voto favorable a su toma en consideración una iniciativa legislativa popular, frente a las 9 que llegaron a esta fase.

Incluso el cambio introducido en el artículo 13.2 por la Ley Orgánica 4/2006, de 26 de mayo, en el sentido de que "La tramitación parlamentaria se efectuará conforme a lo que dispongan los Reglamentos de las Cámaras que podrán contemplar la participación de una persona designada por la Comisión Promotora", ha quedado difuminado al supeditarse a unas modificaciones reglamentarias que todavía no se han producido, como reflejan los artículos 126 y 127 del Reglamento del Congreso de los Diputados. Paralelamente, la reforma del año 2006 hacía desaparecer de entre los requisitos de la iniciativa la incorporación de " $U n$ documento en el que se detallen las razones que aconsejan, a juicio de los firmantes, la tramitación y aprobación por las Cámaras de la proposición de Ley" (artículo 3.2 b en la redacción originaria de la ley). Por tanto, hoy en día, las posibilidades de los promotores de la iniciativa para “explicarse" en el Congreso, son más que limitadas.

${ }^{59}$ Los datos referidos al porcentaje de iniciativas legislativas populares que no superan el trámite de admisión, de recogida de firmas o la toma en consideración, proceden de Martínez Jiménez, Aitor, La iniciativa legislativa popular como instrumento de participación ciudadana en el siglo XXI (Madrid, Fundación Ideas, 2012). 
En lo que se refiere a los parámetros formales, podemos distinguir tres tipos de decisiones en relación con la actuación parlamentaria ${ }^{60}$ : un acto reglado que culmina con el trámite de admisión de la iniciativa una vez que la Mesa examine si se cumplen los requisitos exigidos por la Constitución y la Ley Orgánica 3/1984; un acto libre de las Cortes Generales (el trámite de toma en consideración) que, a diferencia del anterior, no es revisable por el Tribunal Constitucional al basarse en criterios de oportunidad; y un acto intermedio entre los anteriores, como la concesión o no de prórroga para la recogida de firmas ${ }^{61}$.

Por tanto, la Constitución española de 1978 introduce esta figura, pero de una forma limitada, con el objetivo de "fortalecer el carácter representativo del sistema democrático establecido por el texto constitucional y de evitar una posible utilización manipuladora y demagógica de la iniciativa legislativa popular en relación con una serie de materias especialmente sensibles" ${ }^{2}$. Por ello, parte de la doctrina considera que la iniciativa legislativa popular, tal como está regulada en España, no es más que una propuesta de iniciativa legislativa $^{63}$, puesto que todavía cumpliendo todos los requisitos, necesita de un acto de voluntad parlamentaria (la toma en consideración) para comenzar en puridad su tramitación; e incluso, los propios promotores, cuando ya se ha tomado en consideración, pierden todo control sobre su propia iniciativa, no pudiendo enmendarla, pronunciarse sobre las enmiendas de los grupos parlamentarios y, ni siquiera, retirarla.

En este sentido resulta significativo lo ocurrido en la presente legislatura con la iniciativa legislativa popular tramitada como Proposición de Ley de regulación de la dación en pago, de paralización de los desabucios y de alquiler social. Publicado el texto de los promotores en el Boletin Oficial de las Cortes Generales (serie B, № 102-1, de 21 de diciembre de 2012) habiendo rebasado el umbral de las 500.000 firmas, sólo en el último momento consiguió ser tomada en consideración (a pesar de contar con cerca de millón y medio de rúbricas), quedando la propuesta inicial desnaturalizada en la tramitación parlamentaria al subsumirse con un proyecto de ley presentado por el Go-

${ }^{60}$ En este sentido véase el Auto $\mathrm{N}^{\circ}$ 140/1992 del Tribunal Constitucional, de 25 de mayo.

${ }^{61}$ Gutiérrez Vicén, Carlos, Sinopsis del artículo 87 de la Constitución (edición actualizada por Galindo Elola-Olaso, Fernando, Madrid, Cortes Generales, 2006) [visible en Internet: http://www.congreso.es/consti/constitucion/indice/sinopsis/sinopsis.jsp?/art=87\&tipo=2]

${ }^{62}$ Vintró Castells, Joan - Bilbao Ubillos, Juan María, Participación ciudadana y procedimiento legislativo: de la experiencia española a la iniciativa ciudadana europea (Madrid, Centro de Estudios Políticos y Constitucionales, 2011), p. 26.

${ }^{63}$ Aragón Reyes, Manuel, La iniciativa legislativa, en Revista Española de Derecho Constitucional, 16 (1986), p. 290. 
bierno. El resultado fue que los promotores "anunciaron" su retirada, pero la proposición de ley, con un contenido diferente al elaborado por ellos, acabó convertida en la Ley $\mathrm{N}^{\circ} 1 / 2013$, de 14 de mayo, sobre Medidas para reforzar la protección a los deudores hipotecarios, reestructuración de deuda y alquiler social.

Lo anterior debe invitarnos a la reflexión. El planteamiento adoptado en 1978, en el que se buscaba fortalecer a los partidos políticos después de un largo período de dictadura, puede no ser efectivo en un momento de desafección generalizada hacia "los políticos" como el que actualmente se vive en España y en el que la flexibilización de los criterios de utilización de este mecanismo podría servir, a nuestro juicio, para canalizar una parte de esa "frustración" ${ }^{64}$.

Desde nuestro punto de vista no estamos ante un instrumento "inútil". Si de 66 iniciativas legislativas populares presentadas hasta el año 2011 solamente una se convierte en ley $y^{65}$, habrá que reflexionar acerca de la regulación establecida en la ley orgánica, eliminando por ejemplo el trámite de toma en consideración y permitiendo una participación real y efectiva de sus promotores en la tramitación parlamentaria ${ }^{66}$. Si el número de proposiciones de ley con base en el artículo 87.3 Cesp. es pequeño en comparación con el volumen total de los proyectos de ley presentados por el Gobierno y las proposiciones de ley de extracción parlamentaria, habrá que plantearse bajar el número de firmas exigidas y abrir el campo de materias permitidas, bien es cierto que ello requeriría una reforma constitucional que en España únicamente se ha producido en dos ocasiones y que creemos poco probable ${ }^{67}$. En definitiva, pese a los requisitos desincentivadores que se establecen, el

${ }^{64}$ Como dice Larios Paterna, María Jesús, La participación ciudadana en la elaboración de la ley (Madrid, Congreso de los Diputados, 2003), pp. 221-222, "la prohibición sin más de afectación de un elenco tan amplio de materias es sumamente desmotivadora para la utilización de este mecanismo y supone una concepción muy limitada de los derechos participativos por parte de los titulares de la soberanía”.

${ }^{65}$ Ley $\mathrm{N}^{\circ} 8 / 1999$, de 6 de abril, de Reforma de la Ley sobre Propiedad Horizontal, a partir de una iniciativa legislativa popular sobre reclamación de deudas comunitarias (y después de refundirse con otras proposiciones de ley de raíz parlamentaria).

${ }^{66}$ En este sentido, para el ámbito de Cataluña, puede verse la Ley 1/2006, de 16 de febrero, De iniciativa legislativa popular aprobada por del Parlamento catalán, que elimina la toma en consideración, acompasada de una reforma reglamentaria que permite la participación efectiva de los promotores en la tramitación parlamentaria e incluso la retirada del texto.

${ }^{67}$ No tanto por su dificultad procedimental, puesto que el artículo 87.3 puede modificarse por la vía del artículo 167 (tres quintos de ambas Cámaras y referéndum obligatorio solamente si lo pide una décima parte de diputados o senadores), sino por el "temor" de parte de la clase política a que una reforma constitucional pueda abrir el debate sobre otras cuestiones como la forma de estado o la organización territorial. 
número de proposiciones de ley con este origen, centradas principalmente en temas laborales y con dimensión económica, se ha ido incrementando: 2 en la II y III Legislaturas; 6 en la IV; 6 en la V; 9 en la VI, 8 en la VII; y 13 en la VIII ${ }^{68}$. Por lo tanto, si abrimos el campo de juego, podemos dar mejor respuesta a las demandas de la ciudadanía, sin que ello suponga hoy en día un riesgo sustantivo para el funcionamiento de la democracia representativa.

\section{CONCLUSIONES}

La Constitución de 1978 ha proporcionado a España democracia, estabilidad y progreso. Ahora bien, lo anterior no es óbice para reconocer que el constituyente (y después el legislador) introdujo determinados mecanismos para controlar las acciones de ese pueblo en el que reside la soberanía nacional (artículo 1.2 Cesp.). De hecho, pueden traerse a colación las palabras del profesor Torres del Moral, cuando afirma que "desde el mismo momento en que se "concedió" el acceso del pueblo al poder, menudearon las habilidades técnico-jurídicas para restarle valor decisorio [...]. No podemos decir que estas prácticas hayan cesado en nuestros días; en todo caso, se han refinado" 69 .

En este sentido, el importante papel de los partidos políticos (consagrado en el artículo 6 del texto constitucional), configurados como pieza esencial del nuevo régimen democrático en el año 1978, ha condicionado el desarrollo de la democracia representativa y de los instrumentos de democracia directa. No podemos hacer un juicio exclusivamente negativo de ello: el sistema español ha sido mucho más estable que el de otros estados del entorno europeo, y en el ámbito estatal no ha gobernado ningún partido que no haya sido el ganador en votos en la respectiva convocatoria electoral.

Pero los tiempos cambian y las demandas sociales también. La desafección hacia el actual modelo comienza a ser importante y ello debe servir para analizar aquellos aspectos necesitados de mejora y buscar alternativas que lo vuelvan a acercar a la ciudadanía. De esta manera, venimos asistiendo a la formulación de diversas iniciativas que buscan modificar la regulación del sistema electoral o potenciar fórmulas de democracia directa ${ }^{70}$.

${ }^{68}$ Gutiérrez Vicén, Carlos, cit. (n. 51).

${ }^{69}$ Torres del Moral, Antonio, Estado, cit. (n. 4), p. 392.

${ }^{70}$ Dentro del ámbito parlamentario, podemos encontrar en la presente legislatura, por ejemplo, la Proposición de reforma constitucional para reforzar la participación politica y el pluralismo en el régimen electoral, presentada por los Grupos Parlamentarios de la Izquierda Plural (Izquierda Unida, Iniciativa per Catalunya Verds-Esquerra Unida i Alternativa, Chunta Aragonesista) y Mixto (Boletin Oficial de las Cortes Generales, serie B, No 55-1, de 10 de febrero de 2012; posteriormente retirada), abogando por una reforma del sistema electoral (en la elección del Congreso pretende sustituir la 
Así, parece necesario que el sistema electoral sea más proporcional, pero para hacerlo sin tocar la Constitución habría que subir el total de escaños o bajar el mínimo por circunscripción (respetando los márgenes previstos por el artículo 68 Cesp.). Sin perjuicio de que las cosas cambian muy deprisa, y más en el ámbito político, no se vislumbran cambios de ese tipo y la tendencia actual en España es impulsar el recorte del número de diputados (esto es, al menos, lo que sucede en el ámbito autonómico). Del mismo modo, habría que introducir fórmulas para desbloquear las listas, pues el formato de candidaturas cerradas y bloqueadas otorga a las direcciones de los partidos un control casi total sobre las acciones de sus parlamentarios, a la par que impide a la ciudadanía expresar sus preferencias sobre los candidatos incluidos en una lista (la única preferencia posible sería elegir la lista, no los candidatos que la conforman, excepción hecha del Senado que tiene un papel disminuido en el conjunto del sistema). Pero tampoco se ven cambios en esta dirección a corto plazo, más allá de algunas propuestas de incluir el voto preferencial (caso del Partido Socialista, y de modo limitado).

En lo que respecta a las fórmulas de democracia directa la situación sería peor. En el ámbito estatal, descontado el referéndum de ratificación de la propia Constitución, esta figura sólo se ha utilizado en dos ocasiones; al tiempo, este instrumento está vetado para la ratificación o derogación de leyes y ni siquiera se ha utilizado en las dos reformas realizadas a la Constitución hasta la fecha. El otro instrumento estudiado, la iniciativa legislativa popular, fue concebido con unas importantes limitaciones, al excluirse las materias más relevantes (las reguladas por Ley orgánica o la reforma de la Constitución), fijar un elevado número de firmas $(500.000)$ y establecer diversas limitaciones

provincia por la Comunidad Autónoma como circunscripción y el paso de la fórmula d'Hondt a mecanismos de proporcionalidad directa; en cuanto al Senado, formula la elección de los senadores por las comunidades autónomas); por la regulación mediante ley de la defensa de las iniciativas legislativas populares por sus promotores; por abrir la posibilidad de instar la celebración de referendos por el $5 \%$ de los parlamentarios o a través de las iniciativas populares; por dar capacidad a los Presidentes autonómicos para convocar referendos consultivos a petición del Parlamento de su Comunidad Autónoma o a partir de una iniciativa popular (cuestión mediatizada por el actual debate sobre la celebración del referéndum catalán); o por la obligatoriedad de someter a referéndum toda modificación de la Constitución (también las efectuadas por la vía ordinaria del artículo 167). También puede citarse la Proposición de Reforma del Reglamento del Congreso de los Diputados para la creación de la Comisión de Peticiones y Participación Ciudadana, presentada por el Grupo Socialista (Boletin Oficial de las Cortes Generales, serie B, No 74-1, de 1 de junio de 2012), que incluía la posibilidad de celebrar audiencias públicas sobre iniciativas ciudadanas con la participación de sus promotores (de ahí que esta propuesta se conociera como "escaño 351"); no obstante, el Pleno del Congreso rechazó su toma en consideración. 
en su tramitación (como el debate de toma en consideración). Desde nuestro punto de vista urge la reforma de estos instrumentos, pues ello podría dar salida a propuestas que hasta ahora no se canalizan y fortalecería el pluralismo político que consagra la propia Constitución (artículo 1.1).

Al principio de este trabajo advertíamos que España se encontraba en un momento crucial. Es cierto que, desde 1978, ha habido otras crisis políticas y económicas. Lo diferente en este caso es que afecta a todos los elementos del sistema, y lo hace a gran escala: el descontento con el partido que gobierna no se traduce en una mejor valoración de aquél que lidera la oposición; instituciones y actores políticos respetados durante años están hoy bajo sospecha; y la crisis económica es tan fuerte que está causando un profundo impacto social.

Por ello, hay quien apunta la posibilidad de que estemos ante el final de un ciclo $^{71}$. Pero con independencia de que esto vaya a ser así (cosa que dudamos) consideramos que estas circunstancias son precisamente una señal para actuar, haciendo que el sistema democrático funcione mejor y tenga unos cauces de participación que respondan a las demandas ciudadanas del siglo XXI. Desde luego, no creemos que una corrección de los rasgos mayoritarios del sistema electoral español, o una apertura de los instrumentos de democracia directa, vayan a poner en riesgo el sistema político emanado de la Constitución. Al contrario, consideramos que ayudarían a apuntalar el modelo, puesto que uno de los mayores peligros para la democracia representativa española podría venir de no mejorar estas fórmulas de participación directa.

\section{BIBLIOGRAFÍA}

Alzaga VillaAmil, Óscar - Gutiérrez Gutiérrez, Ignacio - Rodríguez ZapaTA, Jorge, Derecho político español según la Constitución de 1978 (4a edición, Madrid, Editorial Universitaria Ramón Areces, 2008), II.

Aragón Reyes, Manuel, La iniciativa legislativa, en Revista Española de Derecho Constitucional, 16 (1986).

Banda Vergara, Alfonso, Democracia representativa y sistema electoral, en Revista de Derecho (Valdivia) 12 (2001) 2.

Bronfman VARgas, Alan, Igualdad del voto y configuración del territorio electoral de los diputados en Chile, en Revista de Derecho de la Pontificia Universidad Católica de Valparaiso, 40 (2013) 1.

Bronfman Vargas, Alan, Mecanismos de democracia directa en Chile: los plebiscitosy

${ }^{71}$ Sobre esto puede verse Casals Meseguer, Xavier, El pueblo contra el Parlamento. El nuevo populismo en España, 1989-2013 (Barcelona, Pasado \& Presente, 2013). 
las consultas comunales, en Revista de Derecho de la Pontificia Universidad Católica de Valparaiso, 28 (2007) 1.

Casals Meseguer, Xavier, El pueblo contra el Parlamento. El nuevo populismo en España, 1989-2013 (Barcelona, Pasado \& Presente, 2013).

Cotarelo, Ramón - Bobillo, Francisco J., El Sistema de Partidos, en Vidal-Beneyto (editor), España a debate, I: La politica (Madrid, Tecnos, 1991).

FERNÁNDEZ SEgADO, Francisco, La correlación entre el tamaño de las circunscripciones y las distorsiones de la proporcionalidad en la elección del Congreso, en Revista de Estudios Políticos, 79 (1993).

GaRrote de MARCos, María, La improbable reforma del sistema electoral del Congreso de los Diputados. Comentario del Informe del Consejo de Estado sobre reforma del sistema electoral, en In Dret, 4 (2009).

Gómez Sánchez, Yolanda, Constitucionalismo multinivel. Derechos fundamentales (Madrid, Sanz y Torres, 2011).

Gutiérrez Vicén, Carlos, Sinopsis del artículo 87 de la Constitución (edición actualizada por Galindo Elola-Olaso, Fernando, Madrid, Cortes Generales, 2006) [visible en Internet: http://www.congreso.es/consti/ constitucion/indice/sinopsis/ sinopsis.jsp?/art $=87 \&$ tipo $=2]$

Larios Paterna, María Jesús, La participación ciudadana en la elaboración de la ley (Madrid, Congreso de los Diputados, 2003).

Llera Ramo, Francisco, El predominio del bipartidismo imperfecto, en Reis, 82 (1998).

Loewenstein, Karl, Teoría de la Constitución ( $2^{\text {a }}$ edición española, Barcelona, Ariel, 1976).

Martínez Arribas, Fernando, Reflexiones sobre la non nata reforma de la Lei de Eleccións ao Parlamento de Galicia, en Dereito. Revista xurídica da Universidade de Santiago de Compostela, 21 (2012) 2.

Martínez Jiménez, Aitor, La iniciativa legislativa popular como instrumento de participación ciudadana en el siglo XXI (Madrid, Fundación Ideas, 2012).

Montero Gibert, José Ramón - Riera SAGrera, Pedro, El sistema electoral español: cuestiones de desproporcionalidad y de reforma, en Anuario de la Facultad de Derecho de la Universidad Autónoma de Madrid, 13 (2009).

Montero Gibert, José Ramón, El debate sobre el sistema electoral: rendimientos, criterios y propuestas de reforma, en Revista de Estudios Políticos, 95 (1997).

Nohlen, Dieter, Sistemas electorales y partidos politicos (México, Fondo de Cultura Económica, 2004).

Oliver Araujo, Joan, Los sistemas electorales autonómicos (Barcelona, Institut d'Estudis Autonòmics, 2011).

Pereira Menaut, Antonio Carlos, Na procura do mellor sistema electoral para Galicia, en Torres del Moral (director) - Martínez Arribas (coordinador), Análise das eleccións autonómicas galegas do 21 de outubro de 2012: Reflexións sobre o sistema electoral (Santiago de Compostela, Andavira, 2013).

Schmitt, Carl, Sobre el parlamentarismo (Madrid, Tecnos, 1990).

Soto BARrientos, Francisco, El desafio de la participación. Referendo e iniciativa legislativa popular en América Latina y Europa (Santiago de Chile, Lom Ediciones, 2013).

Torres del Moral, Antonio, "Prólogo" a Torres del Moral, Antonio (director) - Martínez Arribas, Fernando (coordinador), Análise das eleccións autonómicas galegas do 21 de outubro de 2012: Reflexións sobre o sistema electoral (Santiago de Compostela, Andavira, 2013). 
Torres del Moral, Antonio, Estado de Derecho y democracia de partidos (Madrid, Universitas, 2012).

Vintró Castells, Joan - Bilbao Ubillos, Juan María, Participación ciudadana y procedimiento legislativo: de la experiencia española a la iniciativa ciudadana europea (Madrid, Centro de Estudios Políticos y Constitucionales, 2011). 
